\title{
MANAGEMENT OF COMMUNITY ELDERLY CLUBS FOR IMPROVING WELL- BEING OF THE THAI ELDERLY: A QUALITATIVE STUDY
}

\author{
Kunwadee Rojpaisarnkit ${ }^{1}$ and Yuvadee Rodjarkpai $^{2}$ \\ ${ }^{1}$ Department of Public Health, Faculty of Science and Technology, Rajabhat Rajanagarindra University, \\ Chacheongsao, Thailand, 24000. \\ 2Department of Health Education, Faculty of Public Health, Burapha University, Chonburi, Thailand, 20131
}

Corresponding author: Kunwadee Rojpaisarnkit

Email: kunwadee85@hotmail.com

\begin{abstract}
In Thailand, the elderly club is a public organization that plays an important role in developing the well-being of the elderly in the community. The aim of this study was to 1) examine the management of the elderly club and the characteristics of elderly well-being development activities, 2) investigate the management of the elderly club in developing elderly well-being, and 3) determine the factors affecting the successful management of the elderly clubs and the activities that improve well-being of the elderly. The employed research method was a form of phenomenological research, with data collection conducted via six focus group discussions and in-depth interviews. The participants were club committee members who met the inclusion criteria. Data was analyzed using the content analysis method and its reliability was verified by examining information against relevant literature, view of informants, and experts. Results found most of activities improving elderly well-being focused on health promotion and elder education. There were eight important factors affecting the successful management of the elderly club, i.e. competency of the leader and club committees, committee and member participation, regular activities, support from public health officers, financial self-reliance, external financial support, network partners, and social participation. The research also suggests five important factors affecting the activities that improve elderly well-being, i.e. external financial support, network partners, committee and member participation, social participation, and support from public health officers.
\end{abstract}

Keywords: elderly, elderly club, well-being, management, Thailand.

\section{INTRODUCTION}

Thailand is now classified as an aging society 1,2 with the proportion of the elderly increasing steadily ${ }^{3,4}$. Elderly community clubs play an important role in improving the well-being of aging adults, helping to improve the quality of aging adults' life in the community. For example, the clubs develop the potential of the elderly to be strong and able to perform various daily activities. $^{5}$

Since, the promotion of elderly well-being improvement begins at home and in the local community, the Thai government has placed an emphasis on supporting community participation for improving elderly health, and supporting the operation of elderly clubs in the community. ${ }^{5,6}$ The Council of the Elderly of Thailand define an elderly club as a group of 30 elderly people whose age is over 60 . The club is permitted to have people whose age is between 25 and 59, but the number of these people must be less than a quarter of all members. ${ }^{6}$

An important goal in promoting an action of the elderly clubs is to reduce the number of disabilities that require long-term care. Previous studies have reported that community elderly clubs play an important role in improving the health and well-being of the elderly in the community. ${ }^{7,8}$ However, there are well managed elderly clubs that can be role models for developing elderly development activities in the community, and other clubs that are less well managed. So far, the elderly clubs in Thailand that have been set up are operational and have ongoing activities, half of all clubs had problems in management in many ways. ${ }^{9}$ The elderly club is the cornerstone of the integration of the elderly in the community. ${ }^{10}$ The activities of the elderly club are important to the improvement of the quality of the elderly's life. Also, they provide opportunities for the elderly to use their potential for their own benefits. ${ }^{9,10,11}$

There should be studies on the success of the elderly club management in order to obtain guidelines for strengthening the elderly club in engaging the elderly well-being activities in the community, the lessons learned about the strong elderly club can be applied to the other clubs. Therefore, the aim of this study was to focus on the factors affecting the successful management of elderly clubs at the sub-district level, and to determine the factors that affect health development activities. The results of this study may be used to provide guidelines to improve club 
management of elderly clubs in Thailand and the other ASEAN countries with similar social contexts.

\section{METHODS}

This study used phenomenological research by applying qualitative techniques. Research objectives were: 1) To examine the activities for improving elderly well-being, the network partners, budget sources for organizing the activities, and benefits of the clubs to the elderly, 2) To investigate the factors affecting the club's management to carry out the elderly activities improving elderly well-being, and 3) To determine factors that contribute to the elderly club which performs activities on the development of the elderly health and well-being.

Based on literature review and expert opinions, the success of the management of the elderly club was defined as follows: 1) The elderly health and well-being development activities are determined by their consistency to meet the desired outcomes, 2) Greater than 50\% of the club members participate in the activities organized by the club, 3) The elderly has better well-being compared to the elderly who are not members of the club, and 4) The club has been honored by local or national agencies for their well-being activities.

Samples of the elderly clubs were the community elderly clubs located at the sub-district level in Thailand. Six elderly clubs purposively selected from different regions of Thailand including North (2), South (1), Central and East (2), and Northeast (1). The selection criteria included: 1) the club had been established and active for over five years, 2) the number of members in the club was over 300 people, 3) the committee was selected by the elderly members of the club, 4) had rules, regulations, and club operations, related to the participation of members, and 5) succeeded in managing the club and being accepted by the community for the activities to promote the health and well-being of the elderly.

Participants were the 65 committees of the elderly clubs. The inclusion criteria were: 1 ) the participants have been a member of the club for at least 3 years, 2) the participants have been a committee of the club for at least 1 year, and 3) the participants are willing to provide research information. The exclusion criteria were the participants have been a discrete club membership status. And 32 committees (at least 3 people per club) who participated in establishing the organization of the club activities were the informants of in-depth interviews.

Data collection tools were focus group guideline and semi-structured in-depth interview questionnaire. The focus group discussion questions were: 1) How was the club managed? 2) What activities did the elderly club conduct in improving the health and well-being of the elderly? 3) What did network partners help drive the activities of the elderly club in improving the well-being of the elderly? 4) Where did the budget source of the elderly well-being activities? 5) What were the benefits of having an elderly club in the community? 6) What were the factors that affect the success of elderly club management? 7) What were the factors that affect the success of elderly well-being activities?

The data was analyzed by applying the method of content analysis and the inspection triangulation method based on the theoretical event analysis. Then, the data was categorized into six event types based on the Lofland ${ }^{12}$ conceptual phenomenon framework as follows: 1) Acts are the behavior of a person in a situation that occurred during a specific period of time, 2) Activities is activities that occur in a continuous manner and involve many people, 3) Meaning is to give the meaning of an action or activity by the definition and direction of the action of things, events and characteristics, 4) Participation in activities is a situation where a person joins an activity, situation or incident, 5) Relationship is the relationship between several people in an event studied that takes place over a period of time, and 6) Situation or condition (setting) is a situation in which an action or activity is happening. Initially, the data from the group discussion was grouped, summarized issues, and analyzed to answer research questions. After that, data from the interview will be summarized in order to add more complete information. Once the research conclusions have been drawn up, the researchers verified the research finding by relevant literature reviewed and presented the data to twelve representatives of the informants and five experts.

\section{ETHICS APPROVAL}

This research study was approved by the Ethics Committee on Human Research in Health Sciences, Faculty of Science and Technology, Rajabhat Rajanagarindra University, Certification No. RRUG-HS-2017-0103. 


\section{RESULTS}

The characteristics of the participants in the group discussion are shown in Table 1. The results of focus group discussion and in-depth interview summarized as follows:

\section{Management of the elderly club}

Activities in improving the well-being of the elderly

The characteristics of well-being development activities for the elderly, included (in order): 1) Physical health promotion activities, such as Tai Chi dancing, aerobic dance, folk dance, 2) Mental health, social health and intellectual well-being promotion activities, such as traditional activities during important dates of the community, volunteer activities, 3) A curriculum for improving knowledge, such as making household products. Participation in club activities helping to reduce dissociation and feelings of loneliness in the elderly. Most of the elderly club continuously organized activities according to the needs of their members. These included: 1) General activities, such as exercise on a daily basis, common prayer on religious day, and various volunteer activities, and 2) Capacity development activities, such as training to be an elderly caregiver to take care of the elderly who were bed ridden.

Table 1: Participant characteristics

\begin{tabular}{cllllll}
\hline Characteristics & $\begin{array}{l}\text { Gr.1 } \\
(n=12)\end{array}$ & $\begin{array}{l}\text { Gr.2 } \\
(n=11)\end{array}$ & $\begin{array}{l}\text { Gr.3 } \\
(n=10)\end{array}$ & $\begin{array}{l}\text { Gr.4 } \\
(n=10)\end{array}$ & $\begin{array}{l}\text { Gr.5 } \\
(n=11)\end{array}$ & $\begin{array}{l}\text { Gr.6 } \\
(n=11)\end{array}$ \\
\hline $\begin{array}{c}\text { Gender } \\
\text {-Female }\end{array}$ & 8 & & & & & \\
-Male & 4 & 8 & 7 & 6 & 9 & 8 \\
\hline Age (yrs.) & & 3 & 3 & 4 & 2 & 3 \\
- - $00-69$ & 6 & 6 & 6 & & & \\
$-70-79$ & 4 & 4 & 4 & 3 & 6 & 5 \\
$-\geq 80$ & 2 & 1 & 0 & 0 & 4 & 5 \\
\hline
\end{tabular}

Network partners to drive the activities of the elderly club

Network partners drove the operation of successful activities in the elderly clubs. The network being able to continuously drive the work in the club includes coordination with partner organizations, such as government organizations, private sectors, and the public, to support the operations of the elderly clubs to be sustainable. The important club network partners included (in order): community leaders, Sub-district (Tambon) Health Promotion Hospital, Sub-district (Tambon) Administrative Organizations or the municipalities, community hospitals, religious institutions, educational institutions, private sectors, etc.

\section{Budget sources for the elderly well-being activities}

The club budget operation sources were consisted of: 1) The main budget sources from the subdistrict administrative organizations or the municipalities via budget of the sub-district health insurance fund, 2) Supplementary budget sources, such as the Thai Health Promotion Fund, direct donations, income derived from the activities of the club, i.e., selling of hand-made products.

\section{Benefits of the clubs to the elderly}

Based on the perspectives of the clubs' committee, the benefits of establishing an elderly club included: 1) Maintain good physical health of the elderly by exercise activities, 2) Reduce the occurrence of depression in the elderly by encourage them to participate in club activities, 3) Create opportunities to develop their potential, and 4) Create opportunities to build their self-esteem and self-worth.

\section{Factors affecting the success of the elderly club management}

The factors affecting the management of the club to carry out their activities to improve elderly well-being, included (in order): 1) The competency of the leader and club committee, i.e., leadership and management ability of the club leader, and financial and budget management of the club committee. In addition, the attention of the clubs' board (or the active board) was important in strengthening the elderly club, 2) The participation of the committee and members, including participation in determining the common goals, the club's vision and mission, and participation in club activities, 3) Having regular club activities, such as monthly meetings, daily exercise groups, etc., 4) Support from public health officers in terms of management guidelines and academic knowledge from them, 5) Financial self-reliance for generating income for club activities, such as making products for sale, 6) External financial support, i.e., the budget from the local administration organization, private sectors, etc., 7) The network partners or supporting parties, to organize activities that supports the club operations, 8) Social participation, i.e., the participation of people in the community to organize activities to develop elderly well-being. 
Factors affecting activities to improve elderly well-being

The factors affecting the activities to improve elderly well-being, included (in order): 1) External financial support for organizing elderly health development activities on a regular basis, such as budgets from the Sub-district Administration Organizations, sub-district health insurance funds, budgets from the National Health Security Office (NHSO) of Thailand, etc., 2) The network partners organizing activities to improve the well-being of the elderly, 3) Committee and members participation in joining the health promotion activities of the club, 4) Social participation, or involvement in the activities, which is critical to elderly well-being, 5) Support from public health officers in organizing activities to develop elderly well-being.

\section{DISCUSSION}

The well-being development activities for the elderly were health promotion activities, and improving knowledge based on local contexts consistent with the other study finding that found important activities of the most elderly club were exercise activities (usually with local dance), mind training activities with meditation, etc. ${ }^{11}$ Participated in club's activities or social activities could be predicted a greater decrease in death risk of the elders. ${ }^{13}$ Several research studies have demonstrated that participation in social activities is associated with better mental and physical health, such as a decreased rate of decline in motor function, decreased mobility disability, improvements of depressive symptoms, improved older adult memory function and sleep, reduced rate of cognitive decline, reduced risk of developing dementia, and more longevity. ${ }^{14}$

The factors affecting the successful management of the elderly club were similar to the factors affecting the activities to improve elderly wellbeing but with difference priorities as mentioned above are discussed.

Competency of the club leader and committees These findings correspond with previous research, which investigated the success of running the elderly club, and reported that strong leadership ${ }^{10}$ and committee responsibility could be affected the standard of operation. ${ }^{15}$ Other studies have found that the chairman's management model ${ }^{16}$ and the potential of leaders ${ }^{11}$ can affect the success of an elderly club. However, the factors related to the role of leader and committees were occupation, age, and the duration of holding the position. ${ }^{17}$ The previous studies of a model elderly club found an important step in organizing the vitality promotion activities of the Thai elderly club including awareness and planning, and selfreliant learning. ${ }^{11}$

\section{Committee and members participation}

In accordance with previous research, the participation of the club committee and members in activities were key factors related to the success of the elderly club. ${ }^{9}$ In addition, regularly enhancing the working skills of the committee was also a factor that has been shown to affect the success of elderly clubs. ${ }^{16}$ Some elderly clubs are unsuccessful in their administration because their members do not participate in the operations of the clubs. ${ }^{16}$ The decision to participate in elderly club activities has been demonstrated to be influenced by activities that promote critical skills, activities to promote social skills, activities to promote mental health, and activities that promote physical health. ${ }^{18}$

\section{Regular activities of the clubs}

The results of this study are consistent with previous research that has reported regular continuation of club activities to be necessary to sustain the quality of life in elderly people, and is directly related to the success of the elderly clubs. ${ }^{16,19,20}$ Moreover, the club management procedures can affect the standard of operation in elderly clubs. ${ }^{15}$ The previous studies of a model elderly club found the repetition and execution of activities were continuous and varied. ${ }^{11}$

\section{Support from public health officers}

The support from public health officers or public health workers can affect the success of managing elderly clubs. Indeed, previous research has shown that persuasion by health care providers is a factor in determining elderly club activity participation and promotion of elderly wellbeing. ${ }^{21}$ Service providers who have a good attitude and an understanding towards the elderly, tend to have the appropriate knowledge and skills to impact elderly well-being in the community. ${ }^{22}$

Financial self-reliance for club activities

In accordance with a previous study, the funding by elderly club members was a basic financial self-reliance factor that can affect the operation of the standard of elderly clubs. ${ }^{15}$ One of the problems and obstacles in the operation of the elderly club was an insufficient budget. ${ }^{16}$ Consequently, financial self-reliance is a key factor that can affect the management success of elderly clubs.

\section{External financial support}

This observation agrees with previous research that a supporting budget from the Sub-district (Tambon) Administrative Organization and private sectors was a success factor for elderly clubs in providing services to elderly people. ${ }^{16,19}$

Network partners (to organize club's activities) In line with the previous research, this observation found that support from network partners, and their coordination ability were factors that could affect the strength of elderly clubs. ${ }^{10,16}$ and to provide services to the elders. ${ }^{23}$ 
Moreover, in order for an elderly club to be effective, it must have meaningful collaboration among related stakeholders. ${ }^{19}$

\section{Social participation}

It has previously been reported that participation of the people in the community with the activities of the elderly club affects the success of the elderly club and quality of life of the elderly. ${ }^{9,24}$ The social participation profiles of older adults in club activities are associated with well-being across many aspects of health, which affect the strength of the clubs. ${ }^{25,26}$

\section{CONCLUSION}

This study provided an in-depth understanding of the factors influencing the successful management of elderly clubs and their provision of activities to improve the health and well-being of the elderly across Thai rural communities. There were eight important factors affecting the successful management of the club included (in order), i.e. competency of the leader and club committees, committee and members participation, regular activities, support from public health officers, financial self-reliance, external financial support, network partners, and social participation. And the five important factors affecting the activities to improve elderly well-being included (in order), i.e. external financial support, network partners, committee and members participation, social participation, and support from public health officers.

The findings summarized the factors into two groups: internal factors, i.e. competency of club leader and committee, committee and members participation, regular activities, and financial self-reliance, and external factors, i.e. external financial support, network or partners, social participation, and support from public health officers. Elderly clubs in Thailand, as well as countries with similar social characteristics, may use the findings from the study to formulate guidelines for the development of elderly wellbeing.

Future studies may examine each factor in more detail to help provide a greater understanding of how they contribute to the success of managing an elderly club to develop elderly well-being. Long-term studies should be followed to determine which factors are most important to promote the sustainable well-being of the elderly in the community, based upon the operation of the elderly clubs. Community participatory action research in developing local action plans to manage the various factors for the elderly club in carrying out the elderly well-being activities should be done based on the local contexts.

\section{ACKNOWLEDGEMENT}

The author would like to express sincere appreciation to Rajabhat Rajanagarindra
University for funding this research. The author would also like to thank the elderly club committee who served as the samples for this study.

\section{REFERENCES}

1. World Health Organization. Report on Aging and Health, Geneva: WHO Press, 2015: 25-49.

2. Kumagai S. Thailand's Efforts to Cope with a Rapidly Aging Population. RIM Pacific Business and Industries (Internet) 2019; XIX (71): 2-28.

3. Xu W, Islam S. What Does ASEAN Economic Community Bring to Older Workers? Examining Inequality in Old Age in Thailand's Fast-Ageing Society. Journal of ASEAN Studies 2019; 7(1): 8697.

4. Seangpraw K, Ratanasiripong NT, Ratanasiripong P. Predictors of quality of life of the rural older adults in Northern Thailand. Journal of Health Research 2018; 33(6): 450-459.

5. Sompoo T, Kheovichai K. Development model of enhancing active aging for elder club in Thailand. Dissertation Doctor of Philosophy, Silpakorn University, 2017. www: ithesisir.su.ac.th/ dspace/bitstream/123456789/1373/1/5 5260805.pdf. (accessed 1 Dec 2019).

6. Council of the Elderly of Thailand. Elderly Club Manual. 2016. www: dop.go.th/ download/ know ledge/knowledgeth201617061047321.pd f. (accessed 8 Mar 2020).

7. Rojpaisarnkit K, Kreingkaisakda W. Development of Guidelines for Implementation of the Community for Developing Well-being of the Elderly. Journal of the Association of Researchers 2017; 22(1) (January April): 81-97.

8. Pattana P. Quality of life among those elderly school, Saraburi Province. Independent Study, Master of Public Health Program in Health Promotion Management, Faculty of Public Health, Thammasat University, 2017. www: ethesisarchive. library.tu.ac.th/thesis/ 2017/ TU_2017_ 5817030033_ 6083_ 5988.pdf. (accessed 12 Nov 2019).

9. Polprasert P, Chankong, W. How to Manage the Elderly Club to Success? 
NRRU Community Research Journal 2018; 12(2) (May - August): 26-36.

10. Khammanee J. Key Success Factors of Becoming Strong Elderly Clubs. Master of Social Work in Social Welfare Administration and Policy. Thammasat University, 2015. www: ethesisarchive.library.tu. ac.th/thesis/ 2015/TU_2015

5605034361_3290_2025.pdf. (accessed 12 Nov 2019).

11. Sompoo T, Kheovichai K. Development model of enhancing active aging for elder club in Thailand. Dissertation of Doctor of Philosophy, Silpakorn University, 2017. www: ithesisir.su.ac.th/dspace/handle/123456789/ 1373 (accessed 11 Nov 2019).

12. Lofland J, Lofland LH. Analyzing Social Settings: A Guide to Qualitative Observation and Analysis. Belmont: CA, Wadsworth 1984: 181-203.

13. Wu J, Li J. The impact of social participation on older people's death risk: an analysis from CLHLS. China population and development Studies 2018; 2:173-185.

14. Novek S, Menec V, Tran T, Bell S. Exploring the Impacts of Senior Centres on Older Adults. Winnipeg, MB: Centre on Aging, May 2013. www: gov.mb.ca/ seniors/ publications/docs/ senior_centre_report.pdf (accessed 8 Mar 2020).

15. Rujayakronkul W, Tridech P, Siri S, Tridech C. Factors Related to Operation of Elderly Club with Standard Quality in Nakhon Pathom Province. Journal of Health and Nursing Research 2019; 35(2) (May-August): 118-128.

16. Thammaapipon S, Onlamai N, Tancharoen J. Success Factors of Ban Rai Care Elderly Club Phetchaburi Province. Veridian E-Journal, Silpakorn University 2018; 11(2): 352-365.

17. Songwut $T$, Wasiveerasi $W$, Nuntamongkolchai $\mathrm{S}$. Role of the committee in administering elderly club Uttaradit Province, 2016. www: western.ac.th/

images/HealthK/Research/ A.Role.pdf. (accessed 12 May 2020).

18. Piriyakunkit N, Wanchai A. Decision Making to Participate in the Elderly Club's Activities and Needs for the
Elderly Club's Activities among Elders in Phitsanulok Municipality. Boromarajonani College of Nursing, Uttaradit Journal 2019; 11(1) (JanuaryJune): 238-251.

19. Torut $B$, Pongquan S. Impact of the Elderly Club on the Social Well-Being of the Rural Elderly in the Northeastern Region of Thailand. Poverty \& Public Policy. 2012. www: onlinelibrary. wiley. com/doi/abs/10.1002/pop4.6 (accessed 2 Nov 2019).

20. Pongcharee P. The Development of Aging Union Activities: A Case Study of Nadoon Sub-district, Nadoon District, Mahasarakham Province. Journal of Graduate MCU Khonkaen Campus 2016; 3(1) (January-June): 68-77.

21. Wanchai A, Piriyakunkit N, Srimahunt K. Experiences of Determining Participation in Elderly Club Activities of Older People Living in Urban Areas: A Qualitative Study. Thai Red Cross Nursing Journal 2020; 13(1) (JanuaryJune): 116-128.

22. Artsanthia J, Kampraw P. Modality of Care for the Older Adults in Community. Journal of The Royal Thai Army Nurses 2014; 15(3) (September - December): 123-127.

23. Supromin C, Choonhakhlai S. The provision of public services in municipalities in Thailand to improve the quality of life of elderly people, Kasetsart Journal of Social Sciences 2017; https:// doi.org/10.1016/j.kjss.2017.12.011.

24. Wongprom J, Jongwutiwes K, Prasertsuk $\mathrm{N}$, Jongwutiwes N. Community Participation in the development of Older Persons' Quality of Life. Veridian E-Journal, Slipakorn University 2015; Thai language version in the fields of humanities, social sciences and arts, 8(3) (September - December): 41-54.

25. Dawson-Townsend K. Social participation patterns and their associations with health and wellbeing for older adults. SSM Population Health 2019; 8: 1-9.

26. Aroogh MD, Shahboulaghi FM. Social Participation of Older Adults: A Concept Analysis. International Journal of Community Based Nursing Midwifery, 2020; January, 8(1): 55-72. 